ГCASE REPORT

Volume 16 Supp 12021

DOl: 10.21315/aos2021.16.s1.10

ARTICLE INFO

Submitted: 02/03/2021

Accepted: 27/05/2021

Online: 22/09/2021

\section{Closure of Oronasal Fistulae Post Palatoraphy with Tongue Flap in Bilateral Complete Cleft Lip Palate Patient: A Case Report}

\author{
Menik Sayektia , Liska Barus ${ }^{a}$, Ni Putu Mira Sumarta ${ }^{{ }^{*},}$ \\ Norifumi Nakamurab
}
${ }^{a}$ Department of Oral and Maxillofacial Surgery, Faculty of Dental
Medicine, Universitas Airlangga, Kota Surabaya, Jawa Timur 60132, Indonesia
${ }^{b}$ Department of Oral and Maxillofacial Surgery, Faculty of Dentistry, Kagoshima University, Kagoshima City 890-8544, Japan

*Corresponding author: niputu.mira@fkg.unair.ac.id

To cite this article: Sayekti M, Barus L, Sumarta NPM, Nakamura N (2021). Closure of oronasal fistulae post palatoraphy with tongue flap in bilateral complete cleft lip palate patient: A case report. Arch Orofac Sci, 16(Supp.1): 59-65. https://doi.org/10.21315/aos2021.16.s1.10

To link to this article: https://doi.org/10.21315/aos2021.16.s1.10

\begin{abstract}
Oronasal fistulae are common complication following palatoraphy. There are several surgical procedures to repair oronasal fistulae. However, conventional oronasal fistulae closure technique is not always possible, especially when the surrounding tissue is replaced by fibrotic tissue due to previous palatoraphy. Tissue defects in oronasal fistulae should be replaced with tissues providing good vascularisation such as pedicle tongue flap. A case of pedicle tongue flap used to close oronasal fistulae was reported. Eleven-year-old girl, presented with oronasal fistulae and bilateral alveolar cleft after previous palatoraphy. The oronasal fistulae were closed with pedicled tongue flap. The healing was uneventful, and the division of the pedicle tongue flap was done three weeks later and closed primarily. There was no dehiscence of the wound and masticatory functions were recorded. Vascularised flap such as pedicle tongue flap is a preferred technique to close oronasal fistulae after palatoraphy.
\end{abstract}

Keywords: Intraoral reconstruction; oronasal fistulae; pedicled flap; tongue flap

\section{INTRODUCTION}

Intra oral defects in the oral cavity can be caused by various factors, such as genetics, trauma, infection and iatrogenic (Sahoo et al., 2016). Oronasal fistulae are abnormal communication between oral and nasal cavities occurring after surgical repair. Oronasal fistulae are difficult to treat and has the possibility of recurrence. The incidence of fistulae varies between $5 \%$ to $34 \%$ (Sullivan et al., 2009). After the first repair of cleft palate, oronasal fistulae develop in many of the patients. The problems that arise are depending on the size of the oronasal fistulae. Oronasal fistulae cause issues in nasal regurgitation, vocalisation and oral hygiene which will complicate chronic rhinosinusitis. This condition causes extreme discomfort, and the most common symptoms are food passage through the nasal cavity or the maxillary sinus and air passage through the oral cavity.

Oronasal fistulae closure can be accomplished with palatal flap, tongue flap 
and buccal fat pad. Multiple failures at cleft palate repair left behind scarred palate and only bad quality tissues available for closure. Additionally, the use of buccal fat pad is not indicated for the closure of large defect. As the local tissues are not sufficient for fistulae closure, a tongue flap could be indicated (Nawfal et al., 2014). The technique was introduced for intraoral reconstruction by Lexer in 1909 (Sahoo et al., 2016). The method is recognised for treating defects of the palate (Dec et al., 2013). It relies on the use of a flap constructed from the dorsum of the tongue to close a defect within palate.

The surgery procedure requires two continuous operations, after the closure of oronasal fistulae, the surgeon needs to resect the pedicle tongue flap. The primary contraindications for tongue flaps are psychiatric disorders, mental retardation, and patients with heavy comorbidities, which can affect the efficacy of general anesthesia (Leturc et al., 2017; Strauss \& Kain, 2014).

\section{CASE REPORT}

An eleven-year-old girl patient presented to the Universitas Airlangga Dental Hospital with oronasal fistulae and bilateral alveolar cleft (Fig. 1). The patient was consulted from the orthodontic department with chief complaint of uneven dentition and with a palate defect, and the patient intended to repair them. Originally, the patient was born with cleft lip palate and alveolar. Ten years before, she had underwent surgical repair

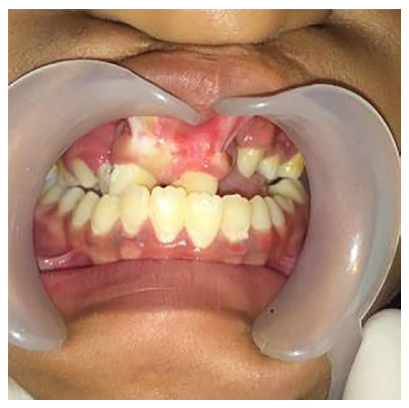

(a)

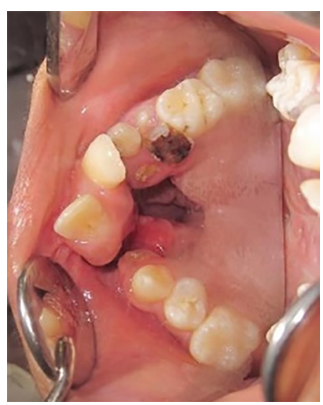

(b)
Fig. 1 Pre-operative intra oral appearance. of the palatal fistulae but with unfortunate results. There was post operation scars on the philtrum area in the maxillofacial region. The upper anterior teeth grew prominently with its position not in the proper arch alignment. There was radiolucent lesion in the anterior region lateral to midline palatal suture indicating bone defect (Fig. 2). The patient was in a good general condition, could eat and drink as other children. However, the patient complained of water flowing through the nose and would choke when drinking.

\section{Patient Management}

\section{First stage surgery}

Oronasal fistulae closure was corrected using the pedicle tongue flap under general anaesthesia. Under local anaesthesia, the vasoconstrictor was infiltrated around fistulae. Incision was done all around fistulae in between the oral and nasal layer (Fig. 3[a]). Then, the nasal layer was dissected and inverted inside. The nasal layer was repaired with 4-0 vicryl to make the floor as recipient site for the flap. Then sutures were passed through the oral layer all around the defect and left ready for suturing with the flap, making the final suturing easier (Fig. 3[b]). The patient was operated under general anesthesia. Pedicle tongue flap was performed first for closure palatal defect then alveolar cleft closure was performed with local flap.

Marking was made in the anterior based tongue flap and incision was given accordingly. The flap was marked with methylene blue, involving the largest possible extent of the back of the tongue, making the flap larger than the defect to be covered, to allow a non-tension suture. The incision was performed with a scalpel blade No. 15, maintaining the flap with $5 \mathrm{~mm}$ to $7 \mathrm{~mm}$ in thickness, to favour vascularisation (Fig. 4). When the flap was reflected, it should incorporate thin sheet of muscle fibres in addition to mucosal and sub mucosal layer to ensure good vascular supply. 


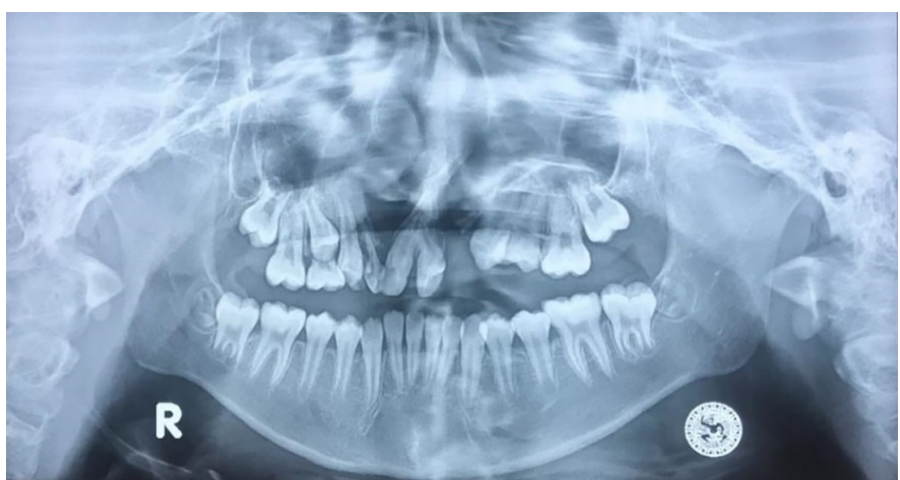

(a)

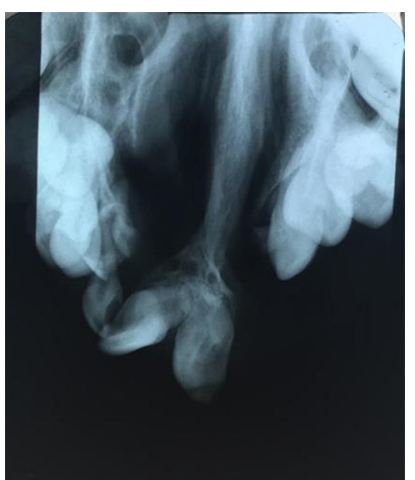

(b)

Fig. 2 Radiograph examination. (a) Panoramic radiograph: Anterior view showing anterior cross bite and bilateral alveolar cleft; and (b) occlusal radiograph showed the anterior teeth misaligned from the proper arch alignment. Palatal view showing anterior palatal defect oronasal fistulae. There was also bilateral alveolar defect.

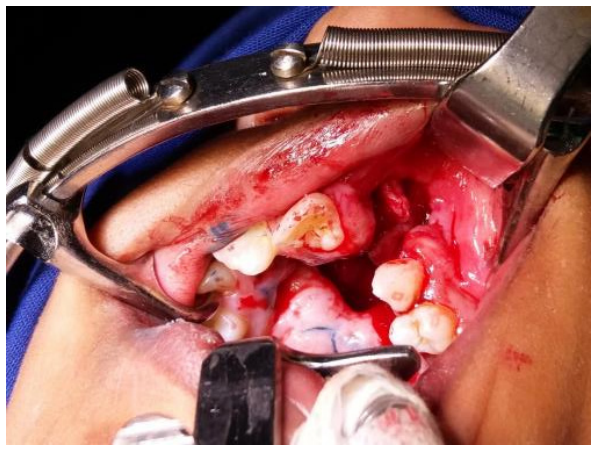

(b)

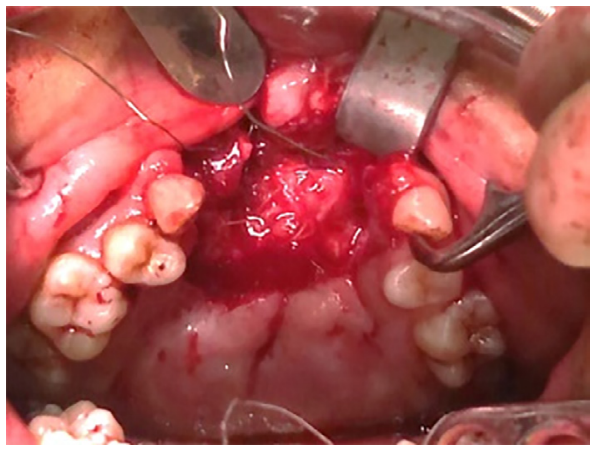

(b)

Fig. 3 Fistulae closure was accomplished using two-layer flaps in the anterior region (a) Alveolar cleft closure with soft tissue flap; and (b) Nasal layer.

The donor site defect was closed primarily with 3-0 vicryl sutures. Care should be taken to check all the bleeding points of donor site and the flap at this stage. Now the flap was positioned against recipient site and sutured with oral layer. Preplaced sutures in the oral layer now passed through the flap margin to secure it firmly. The receptor site was then prepared to receive the flap, with a removal of the superficial epithelium, exposing the underlying connective tissue. Afterward, the flap was adapted to the palate defect and sutured from the posterior to the anterior region. To allow adequate healing, the flap should be retained like this for at least 21 days and the patient was advised to take liquid diet only and avoid excessive mouth opening during that period.

\section{Second stage surgery}

The flap underwent resection after 21 days and the residual defects on the recipient and donor sites were repaired. The pedicle tongue flap was divided under local anaesthesia (Fig. 5). After cutting the pedicle tongue flap, the patient could intake nutrition through her mouth, without nasogastric tube anymore. The defect in anterior palate was closed two months postoperative (Fig. 6[a]) and five months postoperative (Fig. 6[b]). There was no scar fibrosis in the donor site (Fig. 6[c]). There was no flap dehiscence or necrosis in the hard palate tissue. Papilla from the tongue could be observed covering the anterior part of the hard palate, uniting with the 


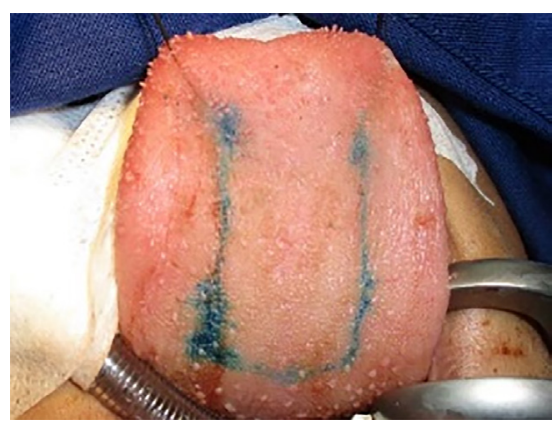

(a)

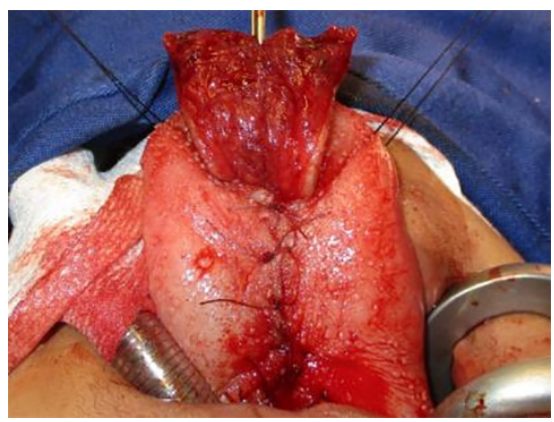

(c)

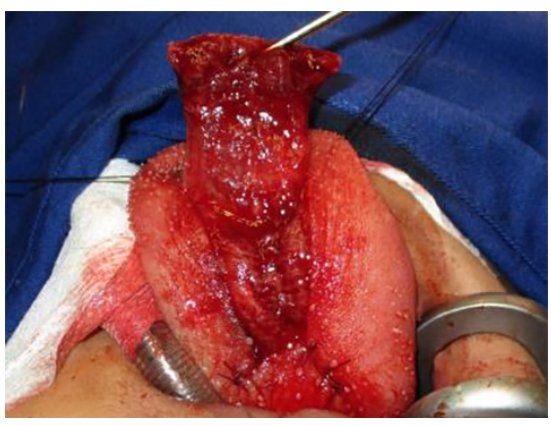

(b)

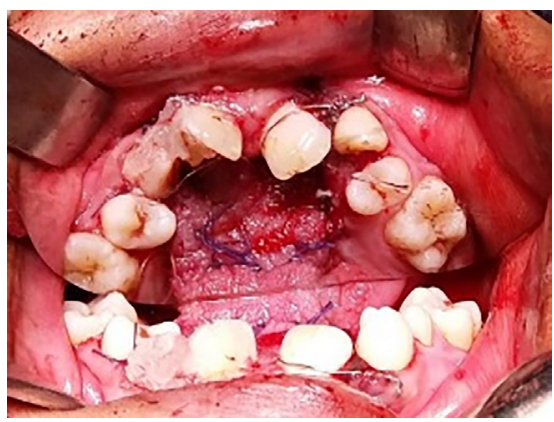

(d)

Fig. 4 Tongue flap. (a) Surgical site marked on the dorsal surface of the tongue; (b) Dorsal tongue flap elevated; (c) The donor site defect is closed primarily; and (d) Donor flap suture to donor site.

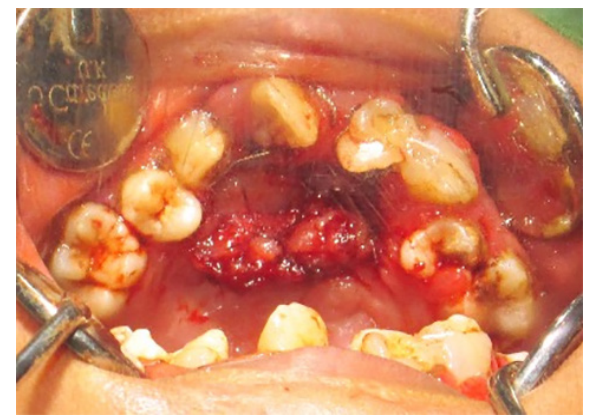

(a)

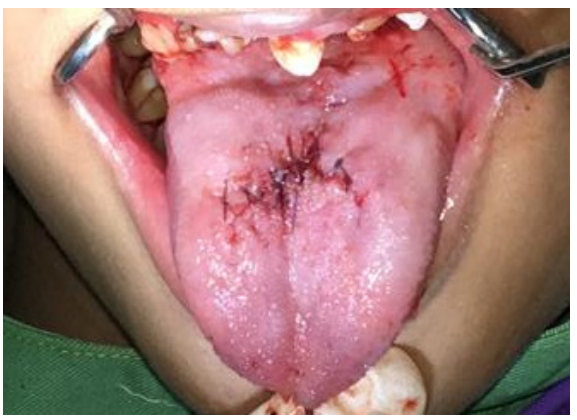

(b)

Fig. 5 Flap division. (a) The pedicle flap was divided; and (b) Donor site after incision.

hard palate tissue, with colour consistent with the surrounding tissues, no redness was observed. The post-operative aesthetics of the donor tongue site had satisfactory result. The patient confirmed that nothing changes in the tongue sensation. There was no interference with speech, and oral hygiene and mastication were unimpaired.
During the last visit to the hospital, the patient did not feel any more water coming out of the nose while drinking. The patient was cooperative and accepted all therapies given, had followed all instructions pre- and post-operation. By good understanding level of the parents and patient, the treatment success rate is high because all procedures were done well. After defect closure, the treatment of the present case would be continued by the orthodontist. 


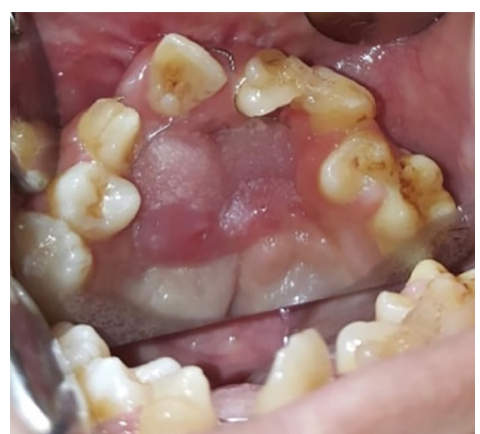

(a)

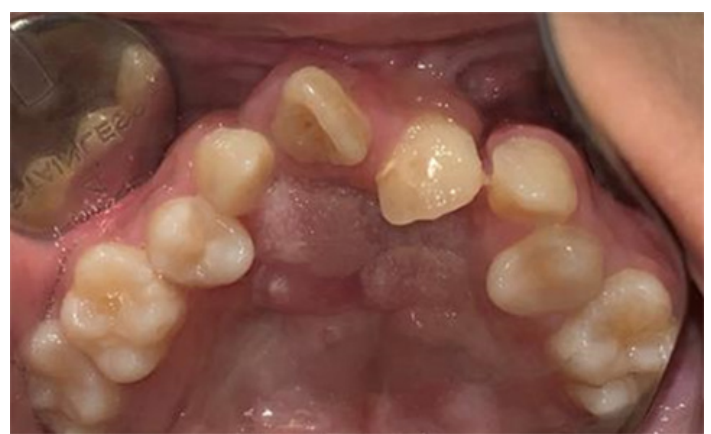

(b)

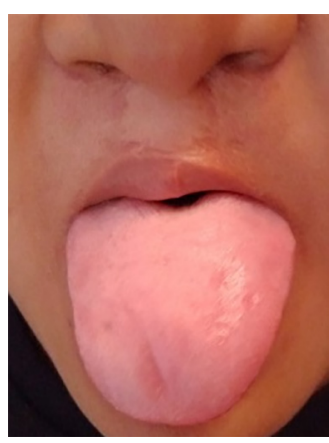

(c)

Fig. 6 Post operation evaluation. (a) Clinical picture of palatal two months post-operative; (b) Five months post-operative; and (c) Donor site after five months post operation showed normal tongue structure and function.

\section{DISCUSSION}

Oronasal fistulae are generally the result of oncologic resections, traumas and congenital abnormalities. Repairing oronasal fistulae defects is one of the most challenging and difficult problems. Based on the size, fistula is classified as tiny $(<2 \mathrm{~mm}$ ), medium ( $3 \mathrm{~mm}$ to $5 \mathrm{~mm}$ ) and enormous (>5 mm). A fistula of more than five $\mathrm{mm}$ in diameter sometimes fails to close ad lib and needs correct surgical closure. The Pittsburgh fistulae arrangement may be described based on the location: Type I: bifid uvula, Type II: soft palate, Type III: junction of the soft and hard palate, Type IV: hard palate, Type V: junction of primary and secondary roof of the mouth, Type VI: lingual alveolar and Type VII: labial alveolar (Bykowski et al., 2015). The fistulae in the present case had enormous size and was Type IV.

The alveolar cleft is bony defect that occurs in $75 \%$ of patients with cleft lip and palate (Cho-Lee et al., 2013). In the present case, alveolar cleft closure was performed first before the closure of palatal defect. The upper jaw anterior teeth were repositioned, and the premaxilla bone was fixated with 0.4 wire. Closure was not performed using bone graft application based on the patient's age as there was no canine germ tooth present.
The choice of procedures is not only influenced by the size and placement of the fistula but also based on the quantity and condition of the graft tissue accessible for repair. Several techniques, such as primary closure, local flaps, tongue flap, buccal fat pad, mucosal grafts and free tissue transfers, have been proposed for the reconstruction of oronasal fistulae (Rahpeyma \& Khajehahmadi, 2015). The tongue flap technique could be created from the dorsal, ventral, or lateral parts of the tongue (Hardwicke et al., 2014). The patient in the present case was treated with the dorsal pedicle tongue flap because the defect is located in the anterior region, thus simplifying application by rotating the flap to cover the defect. Palatal and nasolabial fistulae occur in $5 \%$ to $20 \%$ patients after palatoraphy (Aslam et al., 2015). The recurrence rate of oronasal fistulae is $25 \%$, however, with better skill and technique the recurrence and the incidence rate can be reduced (Mahajan et al., 2014).

The pedicle tongue flap is a recognised technique for treating the palatal defects. This flap provides enough tissue bulk which allows suturing of the flap without tension. The donor location can be closed by primary closure. The advantages in using tongue flap are the availability of adjacent tissues, less donor site morbidity, good vascularity, easier technique to raise and transfer to the recipient site and finally, no scar formation. 
Excellent vascularity ensures viability of the flaps, therefore enhancing the success of simple technique to close the massive palatal defects (Lee \& Alizadeh, 2016; Shash et al., 2016).

The main disadvantages of the pedicle tongue flap are the requirement for a second surgical treatment to detach the pedicle and the need for patient to endure the complications of functional loss like speech and difficulty in swallowing because of the immobile tongue until depedicling (Jeyaraj, 2017). In the present case, after the first surgery, the patient was kept on nasogastric tube feeding for 21 days until the separation of the pedicle. Airway management for the second operation is difficult because the flap was between the palate and the tongue. Nevertheless, dividing the flap under local anaesthesia need patient's cooperation and there could be bleeding into the airway. In order to solve the problems, the operator decided to secure the airway before the division of flap to preclude the probability of bleeding and aspiration into danger airway.

The patient's oral function became briefly restricted because the tongue was temporarily reduced. Among the most common surgical complications are bleeding, hematoma, epistaxis, flap dehiscence, residual fistulae, temporary loss of tactile, and taste sensitivity of the tongue, speech disorders, scar fibrosis, and necrosis (Elyassi et al., 2011). The patient in the present case had shown no flap dehiscence or necrosis in the hard palate tissue. Upon evaluation, there was no changes in tongue sensation and taste perception.

\section{CONCLUSION}

Excellent vascularity and tissue availability that pedicle tongue flap provided had made the tongue flap appropriate for oronasal fistulae closure of medium to large fistulae.

\section{REFERENCES}

Aslam M, Ishaq I, Malik S, Fayyaz GQ (2015). Frequency of oronasal fistulae in complete cleft palate repair. I Coll Physicians Surg Pak, 25(1): 46-49.

Bykowski MR, Naran S, Winger DG, Losee JE (2015). The rate of oronasal fistula following primary cleft palate surgery: A meta-analysis. Cleft Palate Craniofac $\mathcal{F}$, 52(4): e81-e87. https://doi.org/10.1597/14 $-127$

Cho-Lee GY, García-Díez EM, Nunes RA, Martí-Pagès C, Sieira-Gil R, Rivera-Baró A (2013). Review of secondary alveolar cleft repair. Ann Maxillofac Surg, 3(1): 46-50. https://doi.org/10.4103/2231-0746.110083

Dec W, Shetye PR, Grayson BH, Brecht LE, Cutting CB, Warren SM (2013). Incidence of oronasal fistula formation after nasoalveolar molding and primary cleft repair. I Craniofac Surg, 24(1): 57-61. https://doi.org/10.1097/ SCS.0b013e31826d09b5

Elyassi AR, Helling ER, Closmann JJ (2011). Closure of difficult palatal fistulas using a "parachuting and anchoring" technique with the tongue flap. Oral Surg Oral Med Oral Pathol Oral Radiol Endod, 112(6): 711714.

Hardwicke JT, Landini G, Richard BM (2014). Fistula incidence after primary cleft palate repair: A systematic review of the literature. Plast Reconstr Surg, 134(4): 618e-627e. https://doi.org/10.1097/PRS .0000000000000548

Jeyaraj PE (2017). A study on dorsal pedicled tongue flap closure of palatal fistulae and oronasal communications. Ann Maxillofac Surg, 7(2): 180-187. https://doi .org/10.4103/ams.ams_94_17

Lee JY, Alizadeh K (2016). Spacer facial artery musculomucosal flap: Simultaneous closure of oronasal fistulas and palatal lengthening. Plast Reconstr Surg, 137(1): 240-243. https://doi.org/10.1097/PRS .0000000000001904 
Leturc T, Chaux-Bodard AG, Paulus C (2017). Oronasal fistula as a cleft palate sequela: Closure with tongue flap. Case report with review of the literature. Med Buccale Chir Buccale, 23(4): 192-195. https://doi.org/10.1051/mbcb/2017012

Mahajan RK, Chhajlani R, Ghildiyal HC (2014). Role of tongue flap in palatal fistula repair: A series of 41 cases. Indian F Plast Surg, 47(2): 210-215. https://doi. org/10.4103/0970-0358.138950

Nawfal F, Hicham B, Achraf B, Rachid B (2014). Repair of large palatal fistula using tongue flap. Afr $\mathcal{F}$ Paediatr Surg, 11(1): 82-83. https://doi.org/10.4103/0189-6725.129247

Rahpeyma A, Khajehahmadi S (2015). Closure of huge palatal fistula in an adult patient with isolated cleft palate: A technical note. Plast Reconstr Surg Glob Open, 3(2): e306. https://doi.org/10.1097/GOX .0000000000000279
Sahoo NK, Desai AP, Roy ID, Kulkarni V (2016). Oro-nasal communication. f Craniofac Surg, 27(6): e529-e533. https://doi.org/10.1097/SCS.0000000000 002815

Shash H, Al-Halabi B, Jozaghi Y, Aldekhayel S, Gilardino MS (2016). A review of tissue expansion-assisted techniques of cleft palate repair. F Craniofac Surg, 27(3): 760766.

Strauss RA, Kain NJ (2014). Tongue flaps. Oral Maxillofac Surg Clin North Am, 26(3): 313-325. https://doi.org/10.1016/j. coms.2014.05.002

Sullivan SR, Marrinan EM, LaBrie RA, Rogers GF, Mulliken JB (2009). Palatoplasty outcomes in nonsyndromic patients with cleft palate: A 29-year assessment of one surgeon's experience. I Craniofac Surg, 20(Suppl 1): 612-616. https://doi. org/10.1097/SCS.0b013e318192801b 